MAY 2018 ISBN 1595-689X VOL19 No.2 http://www.ajol.info/journals/ajcem

\title{
USE OF STOOL CULTURE AS A NON INVASIVE METHOD FOR THE DIAGNOSIS OF HELICOBACTER PYLORI FROM STOOL OF DIARRHOEIC CHILDREN IN WESTERN NIGERIA
}

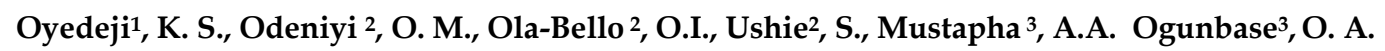 \\ 1. Department of Medical Laboratory Science, College of Medicine, University of Lagos, Nigeria; 2. Department of \\ Medical Microbiology and Parasitology, College of Medicine, University of Lagos, Nigeria; 3 . Department of \\ Paediatrics, Mother and Child Centre, General Hospital, Gbaja- Surulere, Lagos, Nigeria. \\ Corresponding author: K.S .Oyedeji; Tel: +2348066117865; kolaremi903@gmail.com
}

\begin{abstract}
Background: Helicobacter pylori has been associated with chronic diarrhoea, iron deficiency anaemia, growth retardation, gastric malignancies, peptic ulcer disease, and gastritis among children. Diagnosis of this infection has been invasive using biopsies while stool culture is not common or routinely practiced. This study was designed to detect and isolate H.pylori from stool of diarrhoeic children and highlight possible use of such for routine laboratory diagnosis of H.pylori infections.
\end{abstract}

Material and methods: Two hundred and sixty faecal samples obtained from diarrhoeic children were screened for $H$. pylori antigen, using $\mathrm{H}$. pylori stool antigen test kit (HpSA) and cultured on modified DENTS medium. Cholestyramine and nitrobluetetrazolium salt were added to the stool and the medium respectively to aid isolation of $\mathrm{H}$. pylori. Correlation of BMI and $H$. pylori infection of the children was also evaluated.

Results: Twenty-six (10\%) samples showed growth on culture while 91 (35\%) tested positive for H. pylori antigen. Of the 26 children with positive culture, 16 had a low BMI. HpSA has sensitivity and specificity of $11.5 \%$ and $62.4 \%$. There was a significant association $\left(\chi^{2}=12.86, \mathrm{df}=2, \mathrm{P}\right.$-value $\left.=0.004\right)$ between age group of participants and use of HpSA kit.

Conclusion: Stool culture for recovery of $\mathrm{H}$. pylori is feasible in our environment and diarrhoeic children should be screened for $H$. pylori using both HpSA and culture. H. pylori is suggested to be screened routinely especially among children having diarrhoea and are underweight. Albeit, other causes should be eliminated before concluding on the reason for the underweight.

Keywords: Helicobacter pylori, stool culture, HpSA, BMI, Cholestyramine, Nitrobluetetrazolium salt

\section{L'UTILISATION DE CULTURE DES SELLES COMME UNE MÉTHODE NON INVASIVE POUR LE DIAGNOSTIC DE L'HELICOBACTER PYLORI DANS LES SELLES D'ENFANTS DIARRHÉIQUES DANS L'OUEST DU NIGÉRIA}

\author{
Oyedeji1, K. S., Odeniyi 2, O. M., Ola-Bello ${ }^{2}$, O.I., Ushie'2, S., Mustapha ${ }^{3}$, A.A. Ogunbase3, O. A .
}

1. Ministère de la science de laboratoire médical, Collège de médecine, Université de Lagos, Nigeria;

2.Département de microbiologie médicale et de parasitologie, Faculté de médecine de l'Université de Lagos, Nigeria; 3. Département de pédiatrie, Centre de la mère et de l'enfant, Hôpital Général, Gbaja- Surulere, Lagos, Nigeria.

Correspondene: K.S .Oyedeji ; Tel : 2348066117865 ; kolaremi903@gmail.com

\section{RÉSUMÉ}

Contexte : Helicobacter pylori a été associée à la diarrhée chronique, l'anémie, un retard de croissance, de cancers gastriques, ulcère gastro-duodénal, gastrite et chez les enfants. Le diagnostic de cette infection ont été à l'aide de biopsies invasives tout en culture des selles n'est pas commune ou pratique courante. Cette étude a été conçu pour détecter et isoler $H$. pylori dans les selles d'enfants diarrhéiques et mettre en évidence l'utilisation possible d'une telle routine de diagnostic en laboratoire des infections à H. pylori. Matériel et méthodes : Deux cent soixante échantillons de selles diarrhéiques obtenues à partir d'enfants ont été examinés pour l'antigène d'H. pylori, à l'aide de H. pylori antigènes selles test kit (HpSA) et cultivées sur milieu modifié des bosse 
La cholestyramine et nitrobluetetrazolium ont été ajoutés à la selle et le support de l'isolement à l'aide respectivement de $\mathrm{H}$. pylori. Corrélation entre l'IMC et l'infection à H. pylori des enfants a également été évaluée.

Résultats : Vingt-six (10\%) échantillons montrent une croissance de la culture tandis que 91 (35\%) ont été testés positifs pour H. pylori antigène. Des 26 enfants avec culture positive, 16 avaient un faible IMC. HpSA a la sensibilité et la spécificité de $11,5 \%$ et $62,4 \%$. Il y avait une association significative $\left(\chi^{2}=12,86, \mathrm{dl}=2, \mathrm{P}\right.$-value $\left.=0,004\right)$ entre le groupe d'âge des participants et l'utilisation de kit HpSA.

Conclusion : culture des selles pour récupération de $\mathrm{H}$. pylori est possible dans notre environnement et les enfants diarrhéiques devraient être examinés pour $\mathrm{H}$. pylori en utilisant à la fois les HpSA et de la culture. $\mathrm{H}$. pylori est suggéré pour être contrôlés régulièrement en particulier chez les enfants ayant la diarrhée et une insuffisance pondérale. Bien que d'autres co-fondateurs doivent être éliminés avant de conclure sur la raison de l'insuffisance pondérale.

Mots clés: Helicobacter pylori, culture des selles, HpSA, BMI, la cholestyramine, sel de Nitrobluetetrazolium

\section{INTRODUCTION}

Helicobacter pylori is a motile, microaerophilic Gram negative curved rod bacterium that inhabits the gastric mucosa of human stomach. and has been recognized as class 1 carcinogen \{1].The demonstration of its involvement in gastro duodenal pathologies has basically changed the perception of people about the disease [2].Infection with the organism causes peptic ulcers, gastritis, duodenitis and gastric cancers $[3,4,5]$. It has been reported that more than half of the world's population are infected with the organism in both developed and developing countries [5]. Factors that influence the acquisition of $H$. pylori in childhood is basically overcrowding and the socio - economic condition of the parents[ 6-8].The mode of transmission of childhood infection has been found to be common among parents who premasticate food for their children[9]. Most of the available evidence supports person-to-person transmission by faecal-oral, oral-tooral and gastric-to-oral routes [ 9 -12]. In children, gastric inflammation could cause low gastric secretion resulting in impaired "gastric barrier" associated with increased susceptibility to enteric infections, which is a major public health concern linked to diarrhoea, malnutrition and growth retardation in developing countries $[13,14] . \quad H$. pylori infection can be transmitted orally through faecal matter originating from ingestion of waste-tainted food or water [15]. It is also possible that $H$. pylori could be transmitted from the stomach to the mouth through belching or gastro-oesophageal reflux, with common symptoms of gastritis, when small amount of the stomach's contents is involuntarily forced up to the oesophagus. The bacterium could then be transmitted through oral contact [16]. More than half of the world's population is infected with $H$. pylori, which is acquired almost always within the first 5 years of life [17]. The possible routes are faeco-oral, oral-oral and gastro-oral $[16,18]$. Thomas and associates, were able to isolate $H$. pylori DNA and also culture $H$. pylori from human feaces thereby, suggesting faeco-oral transmission[ 19]. Oral transmission has also been proven because
H. pyloriwas isolated from dental plaques and saliva [20].

The prevalence of the disease varies depending on the method of diagnosis. Using serology $15 \%$ and $46 \%$ prevalence rates were recorded among Gambian children aged less than 20 months and 40-60 months respectively [21] and 45\% among Indian children[22]. In Bolivia and Alaska, the seroprevalence were 70\% and $69 \%$ among the 9years old respectively[22] .While, the seroprevalence in preschoolers in Brazil was found to be $69.7 \%$ [23].

In developing countries, studies have suggested that, $H$.pylori may be associated with chronic diarrhoaea especially among children [21] and that $H$.pylori at a young age may induce hypochlorhydria which interferes with the normal acidic barrier in the stomach. However more works need to be done among children in order to determine whether eradication of $H$. pylori reduces the prevalence of chronic diarrhoaea [ 21]. Low socioeconomic status and overcrowding are some of the predisposing factors to the infection [24] .

Diagnosis of $H$. pylori are divided into invasive and noninvasive techniques $[25,26]$. Invasive tests need an Upper Gastrointestinal Endoscopy (UGIE), while the noninvasive techniques do not require endoscopy, but involve methods that make use of stool using kits such as HpSA, stool culture and Urea Breath Tests (UBT) [27]. Generally, biopsy cannot be justified, especially in children, unless one wishes to isolate the organism for antibiotic sensitivity testing or there is a clear clinical indication for UGIE [28]. Moreover, if one opted to test for $H$. pylori by biopsies with UGIE, it require specimen from multiple regions of the stomach, and this may be too stressful for the child. However, a noninvasive and diagnostic tool for detecting $H$. pylori infection is more desirable in pediatrics, because the upper gastrointestinal endoscopies in young children are usually performed in intubation anesthesia or conscious sedation[29] and paediatric endoscope is very costly and not common[ $28,30,31]$. Other non-invasive methods such as Urea Breath Test (UBT) are expensive, difficult to administer in young children and not available in all 
countries though it is as reliable as the invasive methods [13]. Despite the fact that recovery of $H$. pylori from stool culture is laborious, difficult, hence not usually practiced [32] coupled with the fact that culturing of this fastidious organism is relatively difficult, expensive and needs special media for growth; culture still remains the Gold standard [33]. The culture of $H$. pylori has two major advantages: Firstly, it allows antimicrobial susceptibility testing and secondly, the isolates that are obtained by culture can be further studied for its characteristics $[25,34]$.

During culture of $H$. pylori, patients are advised to stay off antibiotics because it is often more difficult to isolate the organism [35]. The addition of Nitroblue tetrazolium (NBT) salts to Columbia agar base (Oxoid) and horse serum (Oxoid), aid in the identification of $H$. pylori colonies cultured on agar media $[25,35]$ while the addition of cholestyramine to the stool help in dissolving the bile in the stool to aid the isolation of H.pylori if present [36] .

In Nigeria, the first work done on H.pylori was by Coker and Akande [37] and it employed invasive method using biopsy. However, the current trend employed in detection and isolation of H.pylori infection is to move from an invasive diagnostic methods to non-invasive method[38]. H. pylori stool antigen (HpSA) test is non-invasive method which only detects the antigen in the faecal sample, and does not include the isolation of the organism[39] The limitation to the use of this method is that antibiotics susceptibility testing cannot be done without isolation of the organism. Hence culture of the organism from the faecal sample needs to be established in routine practice to enable effective management of the infection. This study was therefore designed to detect and isolate H. pylori from stool of diarrhoiec children in Lagos using HpSA test and culture respectively.

\section{MATERIALS AND METHODS}

\section{Sampling Technique:}

The stool samples were collected with a sterile bottle, wide open with attached screw-capped spoon plastic universal containers. A total of 260 stool samples were obtained from diarrhoiec children attending Paediatric Clinics in some health facilities in Lagos metropolis. Consent and assents from parent, guardian and children was sort for respectively depending on age. The parents helped in filling the questionnaires, detailing the weights and heights of the children to enable calculation of their Body Mass Index (BMIs), using the BMI Percentile graph. There was no criterion for hospital selection as samples were collected with only the prognosis of diarrhoea. The inclusion criteria were children within the age range of $\leq 1$ to 16 years having diarrhoea and whose parents consented and the child assented as the case may be before recruitment into the study. Children who have been on antibiotics for two weeks prior to sample collection were excluded.

Sample Processing: The stool samples were processed using detection method- H.pylori stool antigen (HpSA) test kit (SDBIOLINE H.pylori Ag, Germany) and culture method on modified Dent's medium. The stool antigen assay was carried out according to the manufacturer's instructions. Three mls of the assay diluents was transferred into the desired collection tube for use and one gram of faecal sample was emulsified into it using sample collection swab stick provided. The swab was swirled for at least 10 times. This collection swab was discarded after squeezing it against the wall of the collection tube. The resulting suspension was allowed to stand for 5 minutes., then three drops of the suspended supernatant was added into the sample well(s) of the cassette test device and the assay was left to run for fifteen minutes. Appearance of two test lines i.e. " $\mathrm{C}$ " and " $\mathrm{T}$ " which are the Control and Test lines in the result window, indicates a POSITVE RESULT. While one test line " $\mathrm{C}$ ", NEGATIVE RESULT.

\section{Stool culture}

The stool sample was emulsified in phosphate buffered saline and 1gram of cholestyramine was added to the suspension[ 40]. This is to dissolve the bile in the stool. The emulsion was filtered using sterile muslin cloth to remove stool debris. Filtrate further filtered using membrane filter of pore size $0.45 \mu \mathrm{m}$ as it is expected to retain H. pylori if present in the stool. The membrane filter was now cultured for a period of 3 to 12days in a microaerophilic atmosphere $\left(5 \% \mathrm{O}_{2}, 10 \% \mathrm{CO}_{2}\right.$ and $\left.85 \% \mathrm{~N}_{2}\right)$ using the anaerogen gas pak (Oxoid-England) at $37^{\circ} \mathrm{C}$ on modified Dent's medium (Oxoid, England) [41,42] into which Nitroblue tetrazolium salt (NBT) was added[ 43], the latter was supposed to aid the appearance of $H$. pylori on the culture plate, if there is any growth [41]. Plates were checked intermittently for sub culture after the first 3 days through to the $12^{\text {th }}$ day before discarded as no growth. Colonies appearing very tiny, pin head size, with a shining grey features were sub cultured for further testing to characterize $H$. pylori. The isolates were Gram negative spiral rods and produce urease, oxidase, and catalase enzymes during preliminary characteristic reactions.

Antibiotics Susceptibility Testing: The antibiotic susceptibility testing was done using the modified Kirby Bauer [44 ] technique using the disk diffusion method. Two to three colonies of the 
H. pylori isolates were emulsified with physiological saline dispensed into sterile universal container. This suspension was standardised to 0.5MacFarland standard. Isosensitest agar (Oxoid- England) was employed for this test with the addition of $10 \%$ laked horse blood (Oxoid-England). This has been reported to be suitable for carrying out antibiotic susceptibility testing on Helicobacter pylori isolates [45]. The antibiotics used were; Metronidazole, Ciprofloxacin, Clarithromycin, Amoxicillin, Erythromycin, Gentamicin with a herbal extract usually used for peptic ulcer. The seeded plates were incubated under microaerophilic condition overnight at $37^{\circ} \mathrm{C}[44,49]$.

\section{Calculation of the Body Mass Index}

The Body Mass Index of the participants were calculated by taking the weights $(\mathrm{kg})$ against heights in squared $\left(\mathrm{m}^{2}\right)$. The BMIs were extrapolated from BMI Percentile graph (Children BMI scale) for the actual body mass. These were classified into the categories of normal weight, low weight, overweight or obese depending on the BMI of the participants [ 46] (Figure 1).

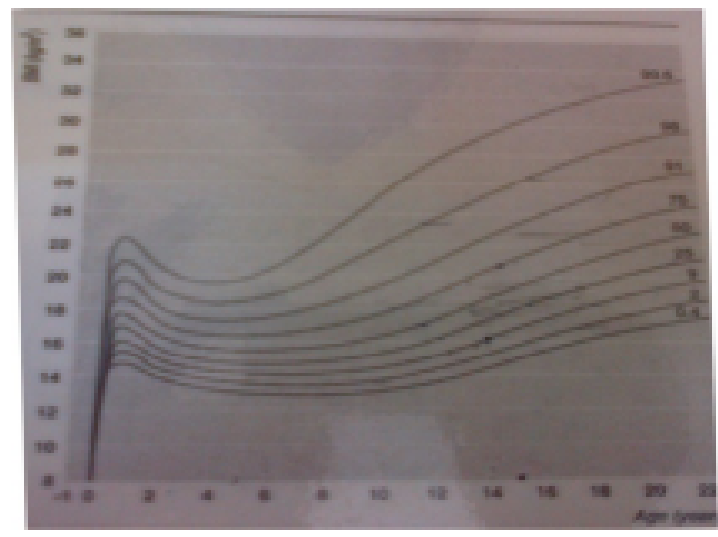

FIGURE1: BMI PERCENTILE GRAPH FOR CHILDRENBMI PERCENTILE GUIDE (Percentile) Underweight: Below 5; Normal weight: 5 - 85; Overweight: 86 - 96; Obese: 97- 99

\section{Questionnaire Analysis}

Information regarding the predisposing factors to H.pylori infection among the population studied was collected through the questionnaires administered to the parents or guardian of the participants. The questionnaires were analyzed using the Statistical Package for Social Sciences (SPSS) version 20 to get the information concerning the possible predisposing factors to $H$. pylori infection.
Ethical Considerations: The ethical approval for this study was obtained from Lagos University Teaching Hospital Health Research Ethics Committee. The consent of the participants was sought before recruitment into the study while confidentiality of all participants' information was maintained.

\section{RESULTS}

Socio-demographic characteristics of participants: Of the 260 participants recruited for this study, 143 $(55.0 \%)$ were males and $117(45.0 \%)$ were females, with a male: female ratio 1: 1.2. The age ranges between 27 days to 16.1 years while the mean age and standard deviation (SD) are $1.45 \pm 0.498$ years (Table 1).

Frequency distribution of detection and isolation of H. pylori from stools of diarrhoeic children: $H$. pylori antigen was detected in 91 (35.0\%) participants using HpSA test kit while the organism was isolated from $26(10 \%)$ of the stool samples using culture (the Gold standard). There was no statistical significant relationship $\left(\chi^{2}=6.98, \mathrm{df}=1, \mathrm{P}\right.$-value $=$ $0.085)$ between the use of culture method and HpSA in diagnosing $H$. pylori infection from diarrhoea stool samples in this study (Table 2).

Comparison of performance characteristics of HpSA
test kit and culture
The performance characteristics for HpSA show a sensitivity of $11.5 \%$, specificity of $62.4 \%$ while the positive predictive value and negative predictive value were recorded as $3.3 \%$ and $86.4 \%$ respectively (Table 3).

Correlation of $\mathrm{H}$. pylori infection with Body Mass Index (BMI) of the studied participants

Of the $26(10 \%)$ H. pylori positive stool samples, 15 $(57.7 \%)$ were underweight (< 5 percentile), $8(30.8 \%)$ had a healthy weights ( 5 - 85 percentile) while 3 $(11.5 \%)$ were obese based on the percentile of $96-99$ (Figure 2).

Correlation of $H$. pylori antigen detection with Body Mass Index (BMI) of the studied participants

Out of the $91(35.0 \%)$ H.pylori positive participants , $73(80.2 \%)$ were underweight ( $<5$ percentile), 8 $(8.8 \%)$ had a BMI percentile range of $5-85,7(7.7 \%)$ had a BMI percentile between ( 86 - 95) while $3(3.3 \%)$ had a BMI percentile range of (96-99), which was an indication of obesity( Figure 3).

Prevalence of $H$. pylori infection among the studied population

From the 260 participants enrolled for this study, only $26(10 \%)$ showed growth of $H$. pylori. after culture for 3-12days (Figure 4). 
TABLE I: SOCIO-DEMOGRAPHIC CHARACTERISTICS OF PARTICIPANTS

\begin{tabular}{|c|c|c|c|}
\hline \multirow[t]{2}{*}{ Variables } & \multirow[t]{2}{*}{ Attributes } & \multicolumn{2}{|c|}{ Respondents } \\
\hline & & Number & Percentage \\
\hline 1.Sex & Male & 143 & 55.0 \\
\hline \multirow{4}{*}{ 2. Age group } & Female & 117 & 45.0 \\
\hline & $\leq 1$ year & 91 & 35.0 \\
\hline & $2-5$ years & 111 & 42.6 \\
\hline & $>5$ years & 57 & 21.9 \\
\hline 3. Number of members living & 3-5 persons & 216 & 83.1 \\
\hline together at home & 6-9 persons & 44 & 16.9 \\
\hline \multirow[t]{4}{*}{ 4. Type of apartment } & One room apartment & 60 & 23.1 \\
\hline & Room and parlor & 60 & 23.1 \\
\hline & Flat & 130 & 50.0 \\
\hline & Duplex & 10 & 3.8 \\
\hline \multirow[t]{3}{*}{ 5. Source of water supply } & Borehole & 255 & 98.1 \\
\hline & Well & 3 & 1.1 \\
\hline & Spring & 3 & 1.1 \\
\hline \multirow[t]{3}{*}{ 6.BMI Percentile } & $<5$ percentile & 156 & 60.0 \\
\hline & $5-85$ percentile & 78 & 30.0 \\
\hline & 96-99 percentile & 26 & 10.0 \\
\hline \multirow[t]{2}{*}{ 7. Washing of hand after toileting } & Yes & 257 & 98.8 \\
\hline & No & 3 & 1.1 \\
\hline \multirow[t]{2}{*}{ 8. Feeding habit (Chewing food for infant) } & Yes & 26 & 10.0 \\
\hline & No & 234 & 90.0 \\
\hline
\end{tabular}

Antibiotics susceptibility patterns of $H$. pylori isolates from the stool samples

Majority of the H. pylori isolates $21(80.8 \%)$ were sensitive to Ciprofloxacin with zone of inhibition size of $35 \mathrm{~mm}$. Eight $(30.8 \%)$ were sensitive to Gentamicin with a zone sizes of $4 \mathrm{~mm}$ while only $5(19.2 \%)$ with a zone sizes of $10 \mathrm{~mm}$ were sensitive to Erythromycin . However, H.pylori showed moderate sensitivity to the other antibiotics used in this study (Table 4). 
TABLE 2: FREQUENCY DISTRIBUTION TABLE SHOWING ISOLATION AND DETECTION OF H. PYLORI AMONG THE STUDIED POPULATION

\begin{tabular}{llcc}
\hline Variables & Attributes & Participants \\
$\mathrm{N}=\mathbf{2 6 0}$ & & Number & Percentage \\
\hline H. pylori stool antigen (HpSA) test & Positive & 91 & 35.0 \\
& Negative & 169 & 65.0 \\
Stool culture status & Positive (H. pylori-isolated) & 26 & 10.0 \\
& $\begin{array}{l}\text { Negative }(\text { H. pylori not } \\
\text { isolated) }\end{array}$ & 234 & 90.0
\end{tabular}

TABLE 3 : COMPARISON OF PERFORMANCE CHARACTERISTICS OF HPSA RAPID TEST TECHNIQUE AND THE USE OF CULTURE METHOD ( GOLD STANDARD)

\begin{tabular}{|c|c|c|c|}
\hline$N=260$ & Culture of & pylori & Total \\
\hline $\begin{array}{l}\text { H.pylori Ag. detection } \\
\text { using HpSA }\end{array}$ & $\begin{array}{l}\text { Number Positive (\%) } \\
\text { (H.pylori isolated) }\end{array}$ & $\begin{array}{l}\text { Number Negative (\%) } \\
\text { (H.pylori not isolated) }\end{array}$ & \\
\hline $\begin{array}{l}\text { Number Positive (\%) } \\
\text { (H. pylori Ag Present) }\end{array}$ & $3(3.3)$ & 88 (96.7) & 91(100) \\
\hline $\begin{array}{l}\text { Number Negative }(\%) \quad(H . \\
\text { pylori Ag absent) }\end{array}$ & 23 (13.6) & $146(86.4)$ & $169(100)$ \\
\hline Total & $26(10.0)$ & $234(90.0)$ & $260(100)$ \\
\hline
\end{tabular}

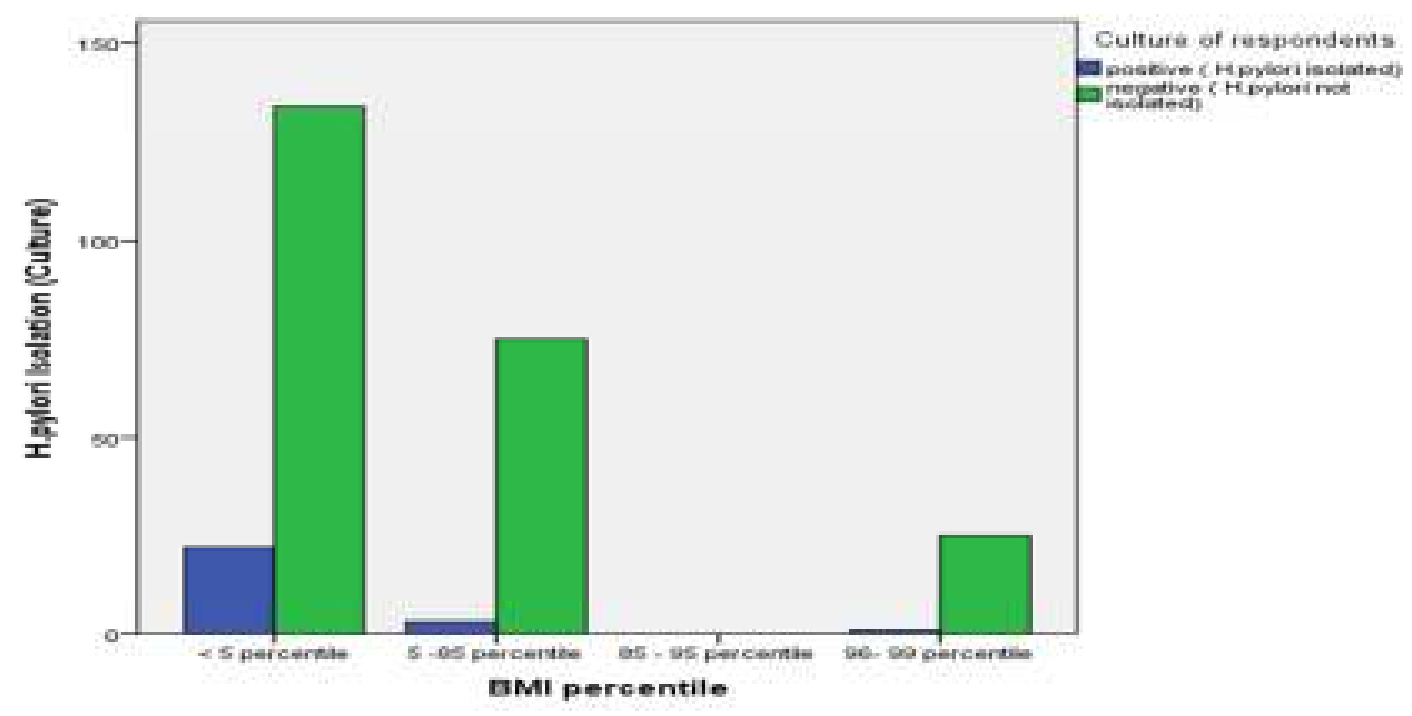

FIGURE 2: SHOWING CORRELATION OF H. PYLORI ISOLATION OF DIARRHOIEC CHILDREN AGAINST BMI PERCENTILE 

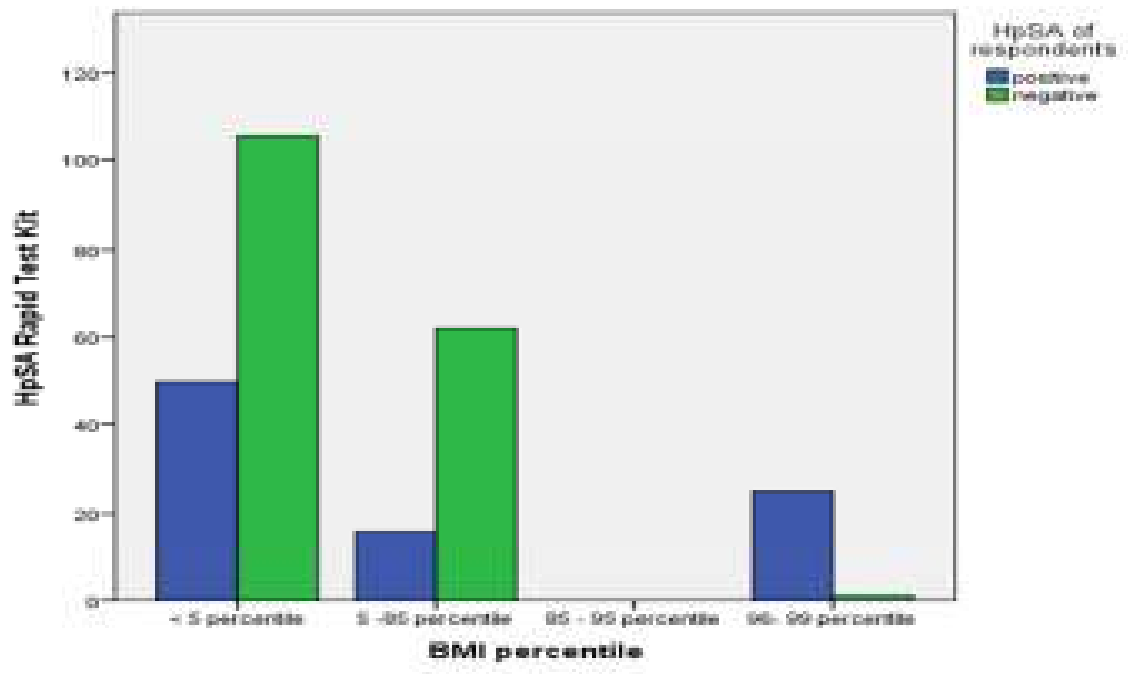

FIGURE 3: SHOWING HPSA RAPID ANTIGEN DETECTION TEST STATUS OF DIARRHOIEC CHILDREN AGAINST BMI PERCENTILE

TABLE 4: ANTIMICROBIAL SUSCEPTIBILITY PATTERNS OF THE H. PYLORI ISOLATES

\begin{tabular}{|c|c|c|c|}
\hline Antibiotics & $\begin{array}{l}\text { Resistance } \\
(\mathrm{N}=26)(\%)\end{array}$ & $\begin{array}{l}\text { Sensitive } \\
(\mathrm{N}=26)(\%)\end{array}$ & Zone size Range $(\mathrm{mm})$ \\
\hline Amoxicillin $(10 \mu \mathrm{g})$ & $11(42.3)$ & $15(57.7)$ & $15-23$ \\
\hline Ciprofloxacin $(5 \mu \mathrm{g})$ & 5 (19.2) & $21(80.8)$ & $34-42$ \\
\hline Clarithromycin(15ug) & $8(30.8)$ & $18(69.2)$ & $25-31$ \\
\hline 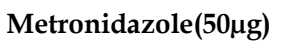 & $11(42.3)$ & $15(57.7)$ & $6-8$ \\
\hline Gentamicin $(10 \mu \mathrm{g})$ & $18(69.2)$ & $8(30.8)$ & $15-18$ \\
\hline Erythromycin $(15 \mu \mathrm{g})$ & $21(80.8)$ & $5(19.2)$ & $25-30$ \\
\hline Herbal extract $A(20 \mu \mathrm{g})$ & $26(100)$ & $0(0)$ & $6-8)$ \\
\hline Herbal extract $B(20 \mu \mathrm{g})$ & $26(100)$ & $0(0)$ & $\begin{array}{l}\text { 6-8) Metronidazole zone } \\
\text { range adapted }\end{array}$ \\
\hline
\end{tabular}

\section{DISCUSSION}

Helicobacter pylori has been found to be associated with several disease conditions among which includes gastritis, gastric ulcer, iron deficiency anaemia, gastric cancer, stunted growth, diarrhoea etc among children $[13,47]$. In this study $H$. pylori has been incriminated as one of the aetiological agents of diarrhoea among children in Western Nigeria with the prevalence of $10.0 \%$ using culture method. This result corroborates similar works done elsewhere $[19,36,38]$. Thus suggesting the implication of H. pylori as gastrointestinal pathogen and the need for the routine screening of diarrhoeic stools for Helicobacter pylori infection rather than reporting no pathogens found especially when Salmonella or Shigella species were not isolated.

Before now there had been emphasis on invasive methods for diagnosis of H.pylori using biopsies. However, this study has detected and isolated $H$.pylori from stool - a non-invasive method using $H$. pylori stool antigen (HpSA) kit and culture technique. The HpSA stool antigen kit is convenient 
especially when dealing with children as it does not involve surgery nor discomfort when using Urea Breath Test, serology or endoscopy. Therefore the inconveniences caused by process of endoscopy, anaesthesia, cost of paediatric endoscopes is reduced or virtually inexistent as stool samples can be used in place of biopsies for the diagnosis of $H$. pylori infection.

In this study a detection rate of $35.0 \%$ using HpSA kit was recorded and this compares with work of Smith et al.[27] where, a detection rate of $36.7 \%$ was recorded among dyspepsia patient undergoing upper gastrointestinal endoscopy . There was a statistical significant relationship between the age of participants and their $H$. pylori infection status as previously inferred by Tahereh et al.[48] where incidence of $H$. pylori was synonymous with increasing age of the studied population. This may be ascribed to increasing biomass of the organism as they multiply in their host with increasing age. Among the participants that were positive by cultural method for H. pylori infection, some of them were underweight and when tested statistically there was a significant association between the presence of H. pylori and low body mass index of these children. This result is in consonance with the result of Oderda et al.[13] implicating $H$. pylori in stunted growth of children in Italy.

The antibiotics susceptibility result obtained tallies with those recorded by Oyedeji et al. [34] and this implies that the quinolones such as ciprofloxacin still shows good activity against H. pylori strains. However, it recorded lower resistance to amoxicillin and metronidazole than what was previously obtained in some studies [34,49]. Though, increase in resistance to metronidazole has also been reported by Henriksen and his associates [50]. This may be explained based on age difference of the study population compared, possible differences in exposure to antibiotics of these populations and antibiotics abuse, where one antibiotic may be used for treating different ailments. Therefore, one can conclude that the $H$. pylori isolates in this study may isolation is desired for possible antibiotics susceptibility testing. It should however, be noted that, prior to the use of HpSA, researcher should alert participants, parent/guardian on the need to abstain from antibiotics, as this may give a false negative result due to the effect of the antibiotics on the organism. Evaluating the culture method, though it has low sensitivity, it is highly specific and desirable when considering antibiotics sensitivity testing. However, there are some challenges posed with this method such as incessant and erratic power outage coupled with the fact that it is cumbersome, despite probably be from supposedly antibiotic-naive children compared to antibiotics exposed adults with subsequent drug abuse and possible self-medication which may be responsible for the discrepancy observed [34,42]. Other factors could be the fact that, the result of antibiotics sensitivity testing of $H$. pylori is determined and or dependent on the type of media, sufficient incubation timing and as well the growth condition.

Current treatment strategies to eradicate $H$. pylori in children have been developed primarily by using data from adults [51]. This is not good enough as it is scientific to always perform antibiotics susceptibility testing for different strains of organisms before determining the best regimen for the treatment of the infection caused by these organisms [57]. This is because organisms from different age groups, location in the body and from different samples may exhibit different sensitivities as is observed in this study $[52,53]$. A triple therapy has been considered to be the standard treatment for children; a proton pump inhibitor combined with two antibiotics has been shown to be very effective in clearing $H$. pylori from the stomach [54]. The current recommendation is treatment with amoxicillin, clarithromycin and a proton pump inhibitor for 2 weeks [55]. However, another triple therapy regimen that are effective in children has been shown to include a proton pump inhibitor combined with Clarithromycin and Metronidazole [55], or amoxicillin and metronidazole combined with Bismuth that would be given for a duration of 2 weeks [56]. This treatment regimen seems to agree with the result of the antibiotics susceptibility testing obtained in this study.

Expatiating on the comparative advantage of the non-invasive method of diagnosis used in this study, it can be suggested that HpSA is easy to perform, patient friendly as no anaesthetics is involved and it is also cheaper compared with Urea Breath Test (UBT). Though the latter may be classified as non-invasive, its cost is similar to those of endoscopy test and not as patient friendly as HpSA stool antigen kit[57]. However, the limitation of HpSA is that, it is a qualitative based test and may not be useful if this it is the most advocated method for diagnosis of Helicobacter pylori based on its comparative advantages over other methods.

On the possible predisposing factors to the transmission of the infection through overcrowding, there was no significant association between number of occupant and $H$. pylori infection in this study. Other possible mode of transmission as postulated by [58,59] Mohammed et al., and Ramy et al., [59,60] such as oral-oral and faeco-oral routes may be implicated as corroborated in this study. 


\section{CONCLUSION}

This study revealed a prevalence of $10 \% \quad H$. pylori infection among children having diarrhoea disease using culture method. This suggests that H. pylori may be one of the incriminating pathogens in diarrhoea disease among children. It also imply that, we may need to routinely screen for $H$. pylori in the stool of children having gastrointestinal problems, especially if no other supposed pathogens such as $E$. coli, Salmonella and Shigella are found.

The diagnosis of $H$. pylori infection using stool culture is more accurate method for diagnosis of the organism, though it has low sensitivity compared with H. pylori stool antigen (HpSA) [57]. Despite the fact that culture is laborious, it is advocated because of its importance in the effective antibiotics management of the infection. This is based on ability

\section{REFERENCES}

1. Kawaguchi K., Matsuo J., Osaki T., Kamiya S., Yamaguchi H. Prevalence of Helicobacter pylori and Acanthamoeba in natural environment. Letters in Applied Microbiology. 2009; Volume 48,Issue 4, 48: 465-471.

2. Marshall MJ., Warren RJ. Unidentified curved bacilli on gastric epithelium active chronic gastritis. Lancet, 1983; 1: 1273-1275.

3. Fritz LE., Slavik T., Delport W. Incidence of Helicobacter felis and the effect of coinfection with Helicobacter pylori on the gastric mucosa in the African population. J. Clin. Microbiol. 2006;44(5): 1692-1696.

4. Figueroa G., Troncoso M., Toledo M. Prevalence of serum antibodies to Helicobacter pylori $\operatorname{VacA}$ and $\mathrm{CagA}$ and gastric diseases in Chile. J. M. Microbiol. 2002;51: 300-304.

5. Ahmed KS., Khan AA., Ahmed I . Impact of household hygiene and water source on the prevalence and transmission of $H$. pylori: a South Indian perspective. Singapore Med. J 2007;48(6): 543-549.

6. Feldman, RA. Epidemiologic observations and open questions about disease and infection caused by Helicobacter pylori. In Achtman $\mathbf{M}$ and Suerbaum $\mathrm{S}$ (eds) Helicobacter pylori: molecular and cellular biology. Wymondham, United Kingdom, Horizon Scientific press, 2001; pp. 29-51.

7. Ndip RN., Malange EA., Akoachere TKJF . Helicobacter pylori antigens in the faeces of asymptomatic children in the Buea and Limber health districts of Cameroon: A pilot study. Trop. Med. Int. Health,2004;9(9): 1036-1040.

8. Dube C., Nkosi TC., Clarke AM. Helicobacter pylori in an asymptomatic population of Eastern Cape Province, South Africa: Public health implication. Rev. Environ. Health, 2009b; 24(3): 249-255. to do the in vitro susceptibility testing of the organism involved. Furthermore, because of the expertise required in culture procedure, incubation time especially $H$. pylori (12days) and its cumbersome nature, $H$. pylori stool antigen (HpSA) rapid test kit may be used instead in detecting the $H$. pylori antigen which means treatment of such cases will be empirical, since no isolation is involved.

Finally, this study has shown that H.pylori is culturable from stool in our environment; it is also involved in other gastrointestinal problems aside peptic ulcer disease and gastritis and may also be a co-factor in stunted growth in children. It is therefore imperative that samples from gastrointestinal tract relating to gastrointestinal problems may also be screened for H.pylori especially when children are involved.

9. Mladenova I., Durazzo M., Pellicano R. Transmission of Helicobacter pylori: are there evidences for a fecal-oral route? Pub Med. 2006; 97(1):15-8.

10. Hardin FJ., Wright RA. Helicobacter pylori: review and update. Arch. Hosp. Physician 2002; 38(5): 23-31.

11. Asrat D., Kassa E., Mengistu Y. Antimicrobial susceptibility pattern of Helicobacter pylori strains isolated from adult dyspeptic patients in Tikur Anbassa University Hospital, Addis Ababa. Ethiop. Med. J. 2004; 42: 79-85.

12. Dube C., Tanih NF., Ndip RN. Helicobacter pylori in water sources: A global environmental health concern. Rev. Environ. Health, 2009a; 24(1): 1-14.

13. Oderda G., Rapa A., Ronchi B. Detection of Helicobacter pylori in stool specimens by noninvasive antigen enzyme immunoassay in children: multicentre Italian study. BMJ, 2000; 320 : 347-348.

14. Thomas JE., Dale A., Bunn JE. Early Helicobacter pylori colonization: the association with growth faltering in The Gambia. Arch. Dis. Child. 2004;89(12): 1149-1154.

15. Santiago p., Moreno Y., Ferrus MA. Identification of Viable Helicobacter pylori in Drinking Water Supplies by Cultural and Molecular Techniques. EPublications. 2015; 20(4): 252 - 259.

16. Mulchandani R., Hans- Olof N., Wadström T . Joshi, BR. Helicobacter pylori : Is it Transmitted Through Faecal-oral or Oral-oral Route? Journal of Pure and Applied Microbiology. 2013; 7(3). p.2429-2438.

17. Megraud, F., Lehours, P., Vale, F.F. The history of Helicobacter pylori: from phylogeography to paleomicrobiology. Journal of Clinical 
Microbiolgy and Infection.2016; Volume 22, Issue 11, Pages 922-927.

18. Gold, BJ. Helicobacter pylori infection in children. Curr Prob Pediatr. 2001;31:247-66.

19. Guetarni H., Bensoltane A. Isolation And Characterization Of Helicobacter pylori Strains From Gastric Biopsies Of Algerian Patients . OnLine Journal of Biological Sciences.2013; 13 (2): 41- 49 .

20. Goosen C., Theron J., Ntsala M. Evaluation of a novel heminesteds PCR assay based on the phosphoglucosamine mutase gene for detection of Helicobacter pylori in saliva and dental plaque. J Clin Microbiol. 2002; 40:205-209.

21. Dulciene MMQ., Andreia MCR., Jean EC. Unintended consequences of Helicobacter pylori infection in children in developing countries. Iron deficiency, diarrhea, and growth retardation.. Journal of Gut Microbes. 2013; Volume 4, Issue 6Pages 494-504 .

22. Kate V., Ananthakrishanan N., Ratnakar C. Anti-H.pylori IgG seroprevalence rates in asymptomatic children and adults form south India. Indian J Med Microbiol. 2001;19:20-25.

23. Rocha GA., Rocha AM., Silva LD. Transmission of Helicobacter pylori infection in families of preschool-aged children from Minas Gerais, Brazil. Trop Med Int Health, 2003;8:987991.

24. Wizla-Derambure N., Michaud L., Ategbo S. Familial and community environmental risk factors for Helicobacter pylori infection in children and adolescents. J Pediatr Gastroenterol Nutr. 2001;33:58-63.

25. Wang YK., Kuo FC., Liu CJ., Wu MC., Shih HY., Wang SS., Wu JY., Ku CH., Huang YK., $\mathrm{Wu}$ DC. Diagnosis of $H$. pylori Infection : Current Option And Developments. World J Gastrolenterol.. 2015; 21 (40):11221 - 11235.

26. Smith SI., Oyedeji KS., Odeniyi OA. Diagnosis of Helicobacter pylori infection among patients with dental caries by stool antigen test. $\mathrm{Br} J$ Biomed Sci. 2006;63(3): 144-145.

27. Smith SI., Omonigbehin EA., Goodluck HA . Diagnostic methods for detection of Helicobacter pylori in Nigeria. Journal Tropical Gastroenterology, 2010;31(2):113-115.

28. Shaman R., Niranga MD., Janaka de Silva H. Helicobacter pylori infection in children. 38: $86-88$ Sri Lanka Journal of Child health, 2009;

29. Braden B., Posselt H., Ahrens P . New immunoassay in stool provides an accurate noninvasive diagnostic method for Helicobacter pylori screening in children. Pediatrics; 2000; 106: 115-117.

30. Tom, RO . Upper gastrointestinal endoscopic findings in adolescents at Lacor hospital, Uganda Afr Health Sci. 2006; 6(1): 39-42.

31. Miller V., Doig C M . Upper gastrointestinal tract endoscopy Personal practice Archives of Disease in Childhood, 1984;59, 1100 -1102
32. Dore MP., Osato MS., Malaty HM . Characterization of a culture method to recover Helicobacter pylori from faeces of patients. Helicobacter ,2000;5: 165- 168

33. Takahiro U., David YG. Diagnosis of Helicobacter pylori using the rapid urease test Ann Transl Med. 2015; 3(1): 9.

34. Oyedeji KS., Smith SI., Coker AO. Antibiotic susceptibility patterns in Helicobacter pylori strains from patients with upper gastrointestinal pathology in Western Nigeria. Br. J.Biomed Sci. 2009;66 (1): 10-3.

35. Wang WH ., Wong WM., Dailidiene D. Aspirin inhibits the growth of Helicobacter pylori and enhances its susceptibility to antimicrobial agents Gut 2003;52:490-495 doi:10.1136/gut.52.4.490

36. Tahereh F., Nargess V., Mehri N. Culture of Helicobacter pylori from stool samples in children. Canadian Journal of Microbiology, 2007; 53(3): 411 - 416, 10.1139/W06-144

37. Coker A.O and Akande, B. Isolation of Campylobacter pyloridis from Nigerian patients with gastroduodenal pathology. West African Journal of Medicine 1989; 8 (2):106 - 110.

38. Mohammad K ., Fereshteh S ., Hossein A ., Naser E.D., Mohammad R.P., Mostafa H., Amir G., Mohammad H.S. Comparison of five diagnostic methods for Helicobacter pylori. Iran J Microbiol. 2013; 5(4): 396 - 401.

39. Abolfazl I., Mohammad - Reza G., Saeed S. Hosein S., Akram H., Mohadeseh M. Stool Antigen Tests for the Detection of Helicobacter pylori in Children. Iran J Pediatr. 2013; 23(2): 138 -142 .

40. Ndip R. N., MacKay W. G., Farthing M.J. G., Weaver L. T. Culturing of Helicobacter pylori from clinical specimens. Journal of Pediatric Gastroenterology and Nutrition. 2003;_Volume 36 - Issue 5 - pp 616 - 622

41. Bury-Moné S., Kaakoush NO Asencio C., Mégraud F., Thibonnier M., De Reuse H., Mendz GL. Is Helicobacter pylori a true microaerophile? 2006; 11(4):296-303.

42. Dulciene M. M.Q., Edilberton N. M., Gilfone A. R. Indicator Medium for Isolation of Campylobacter pylori. Journal of Clinical Microbiology.1987; p. 2378-2379.

43. McNulty C., Robert O., David T., Peter H., Kenneth M., Ashley P., Gillian S ., Louise T., and the PHLS Helicobacter Working Group. Helicobacter pylori susceptibility testing by disc diffusion . Journal of Antimicrobial Chemotherapy. 2002; Volume 49, Issue 4, Pages 601-609.

44. Michael S., Ina T., Cosima L., Jan B., Julia M., Arne K., Mariya V., Thomas W., Dirk S., Peter M. Different antibiotic susceptibility between antrum 
and corpus of the stomach, a possible reason for treatment failure of Helicobacter pylori infection. World J Gastroenterol. 2014; 20(43):16245 - 16251.

45.

Apostolopoulos P., Kousmoutsos I.,
Ekmektzoglou K.. Concomitant versus
sequential therapy for the treatment of
Helicobacter pylori infection: a Greek
randomized prospective study Scand J
Gastroenterol. 2016; 51(2):145-151

46. Mahir G., Ahmet O., Hande O K.. Impact of Helicobacter pylori on growth : Is The Infection or Mucosal Disease Related to Growth Impairment? J Digestive Diseases and Sciences. 2010;Vol. 55 Issue 10, pp 2878 -2886.

47. Dulciene MMQ., Andreia MCR., Jean EC. Unintended consequences of Helicobacter pylori infection in children in developing countries. Gut Microbes. 2013; 4(6): 494-504.

48. Tahereh F., Nargess V., Shayesteh S . Application of a stool antigen test to evaluate the incidence of Helicobacter pylori infection in children and adolescents from Tehran, Iran. Clin. Diag. Lab. Immunol. 2005; p 1094-1097.

49. Clinical and Laboratory Standards Institute( January,2013). Antimicrobial susceptibility testing standards.

50. Henriksen TH., Lerang F., Lia A., Schøyen R. Thoresen T., Berge., Ragnhildstveit E., Tveten Y., Berstad A. Laboratory handling of Helicobacter pylori critically influences the results of in-vitro metronidazole resistance determination. Clinical Microbiology and Infection. 2004; Volume 10, Issue 4, Version of Record online: 10.1111/j.1198-743X.2004.00779.x

51. O'connor A., Taneike I., Nami A., Fitzgerald N., Murphy P., Ryan B., O'connor H., Qasim A., Breslin N., O'moráin C. Helicobacter pylori resistance to metronidazole and clarithromycin in Ireland. Eur J Gastroenterol Hepatol. 2010; 22(9):1123-1127.

52. Shaman R., Niranga MD., Hithanadura J. de Silva. Helicobacter pylori Infection in Children. Saudi J Gastroenterol. 2009; 15(2): 86-94.
53. Muhammad M., Ari F S., Iswan AN., Dadang M., Langgeng AW., Lukman HZ., Fardah A., Willy BU., David S., I Dewa NW., Jimmy BW., Alexander MJS., Fauzi Y., Syifa M., Pangestu A., Ummi M., Hasan M., Yudith AAR., Phawinee S., Nasronudin DR., Rumiko S., Junko A., Yoshio Y. Surveillance of Helicobacter pylori Antibiotic Susceptibility in Indonesia: Different Resistance Types among Regions and with Novel Genetic Mutations. PLoSONE.2016;11(12)

54. Kim MM., Kim N., Lee SH. The effects of probiotics on PPI triple therapy for Helicobacter pylori eradication. Helicobacter. 2008;13:261-268.

55. Rocco MZ., Gabriele B-P., Roberto F., Giovanni G., Enrico R., Franco B. Comparison of 1 and 2 weeks of omeprazole, amoxicillin and clarithromycin treatment for Helicobacter pylori eradication: the HYPER Study. Gut. 2007; 56(4): 475-479.

56. Khurana R., Fischbach L., Chiba N . Metaanalysis: Helicobacter pylori eradication treatment efficacy in children. Aliment Pharmacol Ther. 2007;25:523-536.

57. Malfertheiner P., Megraud F., O'Morain C. Current concepts in the management of Helicobacter pylori infection: The Maastricht III Consensus Report. Gut. 2007; 56(6):772-781.

58. Miftahussurur M., Yamaoka Y. Diagnostic Methods of Helicobacter pylori Infection for Epidemiological Studies: Critical Importance of Indirect Test Validation. Biomed Res Int. 2016; Volume 2016, Article ID 4819423, 14 pages http://dx.doi.org/10.1155/2016/4819423

59. Mohammed MK., Radwa RS., Ramy KA. Helicobacter pylori: A poor man's gut pathogen? Gut Pathogens. 2010; 2:2.

60. Ramy KA., Mohammed MK., Radwa RS. Contaminated water as a source of Helicobacter pylori infection: A review. Journal of Advance Research. Volume 6, Issue 4.2015; Pages 539 547. 